\title{
BMJ Open Long-term effect of physical activity on health-related quality of life among menopausal women: a 4-year follow-up study to a randomised controlled trial
}

\author{
Kirsi Mansikkamäki, ${ }^{1,2}$ Jani Raitanen, ${ }^{1,3}$ Clas-Håkan Nygård, ${ }^{3}$ Eija Tomás, ${ }^{4}$ \\ Reetta Rutanen, ${ }^{3}$ Riitta Luoto ${ }^{1}$
}

To cite: Mansikkamäki K, Raitanen J, Nygård C-H, et al. Long-term effect of physical activity on health-related quality of life among menopausal women: a 4-year follow-up study to a randomised controlled trial. BMJ Open 2015;5:e008232. doi:10.1136/bmjopen-2015008232

- Prepublication history for this paper is available online. To view these files please visit the journal online (http://dx.doi.org/10.1136/ bmjopen-2015-008232).

Received 20 March 2015 Revised 23 July 2015 Accepted 28 July 2015

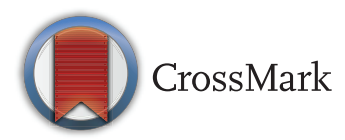

${ }^{1}$ UKK Institute for Health Promotion Research, Tampere, Finland

${ }^{2}$ Tampere University of Applied Sciences, Tampere, Finland

${ }^{3}$ School of Health Sciences, University of Tampere, Tampere, Finland

${ }^{4}$ Tampere University Central Hospital, Tampere, Finland

Correspondence to Kirsi Mansikkamäki; kirsi.mansikkamaki@uta.fi

\section{ABSTRACT}

Objectives: The aim of the study was to explore the long-term effects of physical activity intervention on quality of life (QoL) 4 years after an original randomised controlled trial (RCT).

Design: Cohort study after an RCT.

Setting: 95 of the 159 women from the original RCT participated in weight, height and waist circumference measurements, performed the UKK $2 \mathrm{~km}$ Walk Test and completed the SF-36 Health Survey questionnaire. Multilevel mixed regression models were performed in order to compare the original and current group in an RCT setting.

Participants: There were 159 participants in the original RCT; 2.5 years later, 102 of the women responded to a questionnaire and 4-year after the trial, there were 95 respondents. The inclusion criteria in the original RCT were: being symptomatic, experiencing daily hot flushes, age between 40 and 63 years, not using hormone therapy now or in the past 3 months, sedentary lifestyle and having last menstruated 3-36 months earlier.

Main outcome measure: Health-related QoL as measured with the SF-36 instrument.

Results: Women in the intervention group had a significantly higher probability of improved physical functioning (OR $1.41 ; 95 \% \mathrm{Cl} 1.00$ to 1.99 ) as compared with women in the control group. In addition, women in the intervention group had higher odds of good role functioning (OR $1.21 ; 95 \% \mathrm{Cl} 0.88$ to 1.67$)$, physical health $(\mathrm{OR} 1.33 ; 95 \% \mathrm{Cl} 0.96$ to $1.84)$ and general health $(\mathrm{OR} 1.14 ; 95 \% \mathrm{Cl} 0.81$ to 1.62), relative to women in the control group, although the differences did not reach statistical significance.

Conclusions: Women in the intervention group showed positive long-term effects on physical and mental dimensions of QoL after 4 years.

Trial registration number: ISRCTN54690027.

\section{INTRODUCTION}

Many physiological and psychological signs and symptoms occur in the lives of

\section{Strengths and limitations of this study}

- The core strengths of the study are its prospective study design and repeated assessments of physical activity behaviour at several time points after intervention.

- Our study underlines the importance of physical activity during menopausal transition.

- The response rate $(59.7 \%)$ was low and women with an adverse lifestyle were more likely to be found among non-responders.

middle-aged women. ${ }^{1}$ A positive association between physical activity (PA) and quality of life (QoL) has been explored in many studies. ${ }^{2-7}$ PA has been associated with lower rates of cognitive and physical decline among postmenopausal women. ${ }^{8}$ In addition, PA appears to have positive effects on work ability, both short and long terms. ${ }^{9}$ Hormone therapy (HRT) is widely used as treatment for menopause symptoms, even though exercise has been deemed an alternative option for alleviating their symptoms and improving QoL in midlife. ${ }^{1}{ }^{10} \mathrm{In}$ an 8-year follow-up study, PA has been found to be a significant factor among menopausal women who had stable weight or were highly educated. ${ }^{4}$ Increasing one's level of PA during menopausal transition and the postmenopausal period or at least maintaining the recommended level has also been suggested to reduce various psychological symptoms. ${ }^{11}$

We previously reported results from our menopausal health and PA intervention randomised controlled trial (RCT) ${ }^{6} 12$ examining aerobic training, and improved menopausal and health-related QoL among menopausal women. Women in the intervention group showed significantly larger decrease in the frequency of night-time hot flushes. These 
findings were based on information collected through mobile phone diaries. Additionally, the diaries pointed to better sleep quality among women in the intervention group as compared to those in the control group. ${ }^{7} \mathrm{We}$ also reported that the 6-month exercise intervention had effects on work ability $2 \frac{1}{2} 2$ years after the RCT. ${ }^{9}$

The aim of the follow-up study reported here was to explore the long-term effects of the PA intervention on QoL 4 years after the RCT.

\section{MATERIALS AND METHODS}

The study population consisted of a sample of women who participated in a follow-up 4 years after the beginning of the trial, which was in $2009 .{ }^{6}$ The intervention study in 2009 was a RCT (ISRCTN54690027, http:// www.controlled-trials.com/) in which the women were randomised into an intervention and a control group. Criteria for inclusion in the intervention study were: being symptomatic, experiencing daily hot flushes, age between 40 and 63 years, not using HRT now or in the past 3 months, having a sedentary lifestyle (with aerobic training under twice a week) and having last menstruated 3-36 months earlier. Women who were physically active (exercising two or more times a week, at least $30 \mathrm{~min}$ at a time); whose body mass index (BMI) was above $35 \mathrm{~kg} / \mathrm{m}^{2}$; or who had coronary heart disease, orthopaedic or other diseases preventing them from exercising, were excluded from the study. Further, women who were using medication influencing heart rate, or using $\beta$-blockers, were excluded, since they would have biased the results pertaining to heart rate. Menopausal status was verified via assay of plasma follicle-stimulating hormone (FSH exceeding $30 \mathrm{IU} / \mathrm{L}$ ). Before the trial began, daytime and night-time hot flushes were recorded in a 2-week diary, with the women instructed to record a sensation of warmth, with or without concomitant sweating, as a hot flush, and the daily frequency of hot flushes before the intervention was estimated. During the intervention, the number of hot flushes, both daytime and night-time, was calculated. In total, 159 women participated in the study, and the duration of the intervention was 6 months. ${ }^{6}$

The women in the intervention group engaged in aerobic training four times a week, with 50 min of exercise each time. They were instructed to exercise at a level of about $64-80 \%$ of maximal heart rate, whereas the women in the control group were instructed to keep their PA habits unchanged. In the intervention group, at least two PA sessions had to consist of walking or Nordic walking, while the other sessions could include walking, Nordic walking, skiing, jogging, cycling, swimming, aerobics and/or gymnastics. The intervention primarily included walking because earlier trials showed it to have favourable effects on health among menopausal and postmenopausal women. ${ }^{13}$ Information on hot flushes and aerobic training was collected via mobile phone questionnaires twice a day. Responses were automatically transferred to digital format via $3 \mathrm{G}$ technology. ${ }^{14}$ The SF-36 Health Survey questionnaire was used to measure health-related QoL. This questionnaire has been validated in Finland ${ }^{15}$ and is known to be a reliable measure of QoL. It is composed of 36 items, addressing eight dimensions of QoL: physical functioning, physical role limitations, bodily pain, general health, vitality, social functioning, emotional role limitations and mental health. ${ }^{6}$ The scores for each of the eight dimensions were transformed linearly to a scale ranging from 0 (maximal impairment) to 100 (best QoL). ${ }^{6}$

The first follow-up questionnaire was posted to the participants $2 \frac{1}{2}$ years after the intervention began, and 102 of the 159 women responded. Results from this follow-up questionnaire have been reported in earlier work. $^{9}$

Four years after the beginning of the trial, the participants $(n=159)$ were asked to take part in the second follow-up study. After this request, 95 of the women responded to the questionnaire and participated in the measurements. All the participants gave written consent. Weight, height and waist circumference were measured with lightweight clothing by staff of the UKK Institute, and the UKK $2 \mathrm{~km}$ Walk Test was performed. ${ }^{16}$ The participants completed the SF-36 Health Survey questionnaire on health-related QoL, at home. ${ }^{15}$ In addition, they carried a Hookie accelerometer for a week, in order to measure their daily PA. Also, the women were asked to take notes, in a 1 week diary, about the type and intensity of their PA, and to note the exercise time. Specific questions related to accelerometer use and the UKK 2-km Walk Test will be reported on in a separate article. In addition, the participants were asked to use a 1 week diary to note the number of daytime and nighttime hot flushes experienced, the time they fell asleep and woke up, and their judgement of their sleep quality. A flow chart of the participants' data is shown in figure 1 .

\section{STATISTICAL ANALYSIS}

The characteristics of the study population are described best in terms of means and SEMs, or frequencies and percentages (table 1).

Multilevel mixed effects logistic regression models were constructed to account for the within-subject correlation between four time points. The odds model was used for analysis of the association between the outcomes both on the physical dimensions (physical functioning; role functioning, physical; freedom from pain; and physical health) and on the psychological dimensions (role functioning; emotional; vitality; emotional well-being; social functioning; general health; and mental health) over time and between the intervention versus the control group. Multilevel linear regression models could not be used, because the distributions of SF-36 variables were skewed or discrete. Since the conditions necessary for the use of multilevel ordinal logistic 
Figure 1 Participant flow chart.

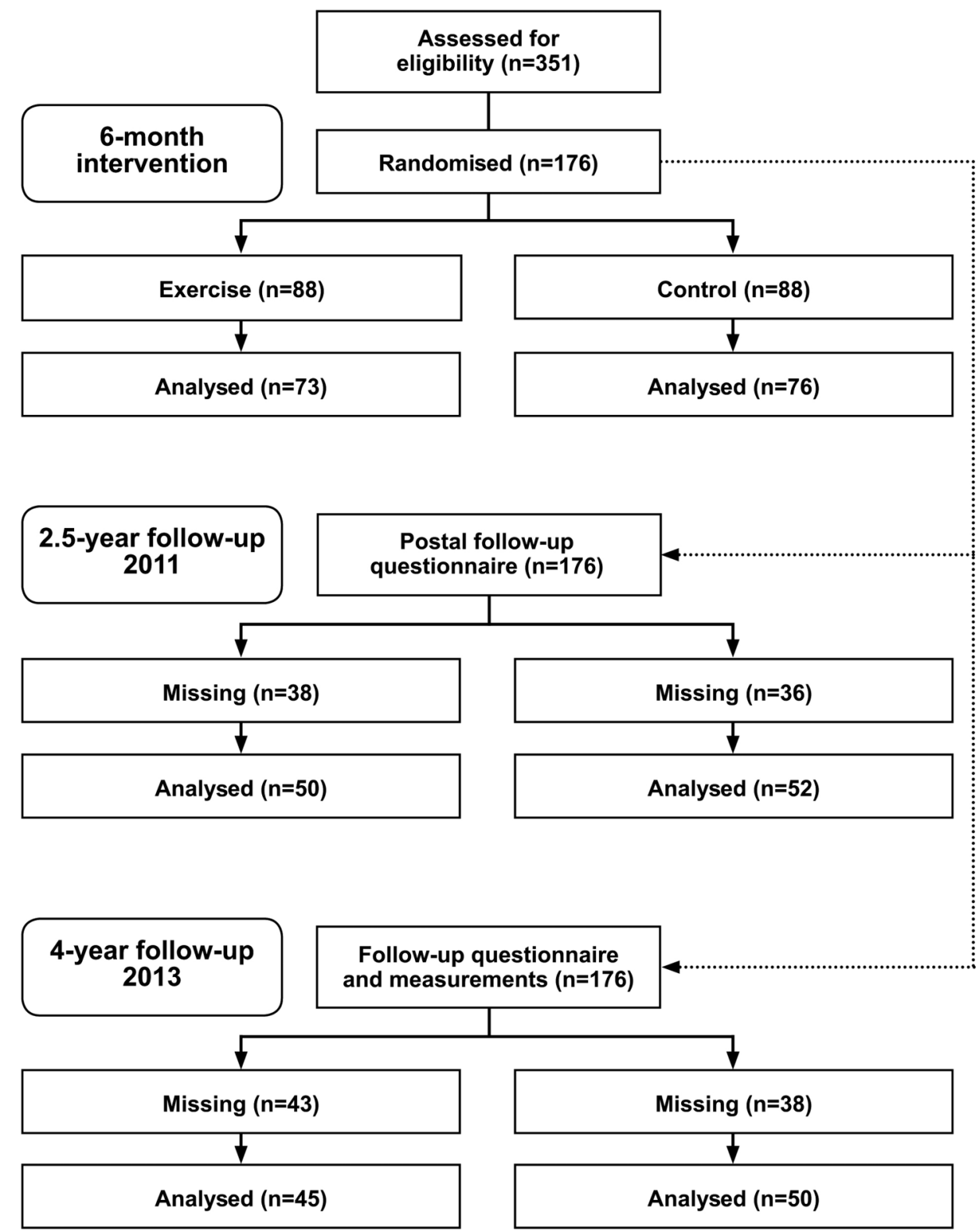

regression models were not met, these models could not be used either.

The multilevel model for dichotomous outcome $y_{i j}$ at time $\mathrm{i}$ for person $\mathrm{j}$ can be expressed as

$\operatorname{logit}\left\{\operatorname{Pr}\left(\mathrm{y}_{\mathrm{ij}}=1 \mid x_{\mathrm{ij}}, \varsigma_{\mathrm{j}}\right)\right\}=\beta_{1}+\beta_{2} \mathrm{x}_{2 \mathrm{j}}+\beta_{3} \mathrm{x}_{3 \mathrm{ij}}+\beta_{4} \mathrm{x}_{2 \mathrm{j}} \mathrm{x}_{3 \mathrm{ij}}+\varsigma_{\mathrm{j}}$,

where $x_{2 j}$ represents group, $x_{3 i j}$ represents time, $x_{i j}=\left(x_{2 j}\right.$, $\left.\mathrm{x}_{\mathrm{ij}}\right)^{\prime}$ is a vector containing both covariates, and $\zeta_{\mathrm{j}}$ is a person-specific random intercept. This model allows for a difference between groups at baseline $\beta_{2}$, and linear changes in the log odds of outcome over time with slope $\beta_{3}$ in the control group and slope $\beta_{3}+\beta_{4}$ in the intervention group. Therefore, $\beta_{4}$, the difference in the rate of improvement (on the log odds scale) between groups, can be viewed as changing over time between groups. ${ }^{17}$ Also second-order and third-order functions of time were included in the model, for testing of whether a model with a non-linear effect improved the fit. A likelihood-ratio test was used for models' comparison, to identify the model fitting best. The parameter estimates were presented as ORs with $95 \%$ CIs.

The proportions for the physical and mental dimensions of QoL by time are shown in figures 1 and 2. The outcomes of QoL dimensions were classified in two categories according to medians. Proportions of women having higher or equal score than median are shown in figures. Higher score defines more favourable health state. The Wilson score method without continuity correction:

$$
\frac{\left(2 n p+z^{2} \pm z \sqrt{\left(z^{2}+4 n p q\right)}\right.}{2\left(n+z^{2}\right)}
$$

where $\mathrm{n}$ denotes the sample size, $\mathrm{p}$ is a single proportion, $q=1-p$ and $z$ denotes the standard normal deviate 
associated with a two-tailed probability $\alpha$, was used to calculate the $95 \%$ CIs for the proportions in figures 1 and $2 .{ }^{18}$

The significance of all tests was determined to be at a $\mathrm{p}$ value $<0.05$, and data analyses were performed with Stata Statistical Software, Release 12 (from StataCorp LP, College Station, Texas, USA).

In these models, we used all available responses from women even if they had not responded to all points of data collection. As sensitivity analyses, we performed multilevel mixed effects logistic regression models also for women who responded to all four time points $(\mathrm{N}=75)$. We also analysed the results by using only the second follow-up (without 2.5 years follow-up).

\section{RESULTS}

Most of the participants $(68 \%)$ were employed or parttime workers $(9 \%)$ when the intervention began. Over the course of the 4 years, $7-20 \%$ of the women were in part-time employment.

The women participating in the 4-year follow-up were, on average, 58 years of age, and their mean BMI was $26-27 \mathrm{~kg} / \mathrm{m}^{2}$. In the follow-up, no significant change in BMI was observed. The proportion of women using HRT was higher at the 4-year follow-up point than before the intervention. In the follow-up, no significant differences were observed in use of blood pressure and cholesterol medication. Use of headache medicine and other painkillers, sedatives and sleeping pills, and antidepressants, decreased within the intervention group and also among those in the control group. The intervention and the follow-up showed increased use of vitamins and mineral preparations in the intervention group (from $55.1 \%$ to $68.9 \%$ ) while in the control group their use declined (from $51.9 \%$ to $34.0 \%$ ); these results are presented in table 1.

The women in the intervention group had a greater likelihood of improvement on the various QoL dimensions from baseline to the end of 4-year follow-up. Overall, the results show that women in the intervention group sustained their improved QoL more often than women in the control group did. Figures 2 and 3 show the proportions observed for the physical and mental dimensions of QoL.

With the follow-up measurements, we found that women in the intervention group displayed an improvement in physical functioning (OR 1.41; 95\% CI 1.00 to 1.99) when compared with the control group. However, no significant differences were observed between groups for the other variables, as is indicated by table 2. Results for mental dimensions of QoL did not reach statistical significance (shown in table 3 ).

The women who did not participate in the 21/2-year and 4-year follow-up studies ( $\mathrm{N}=47,28.1 \%)$ were younger at baseline (53.0 years, in contrast to 54.5 years), they had a higher BMI (28.0, in contrast to 26.3) and they were

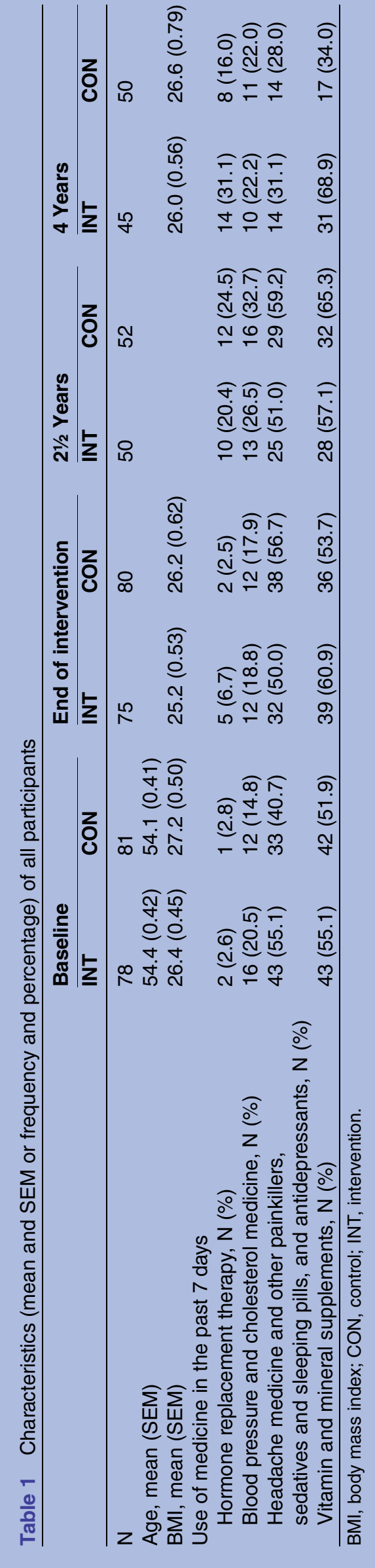



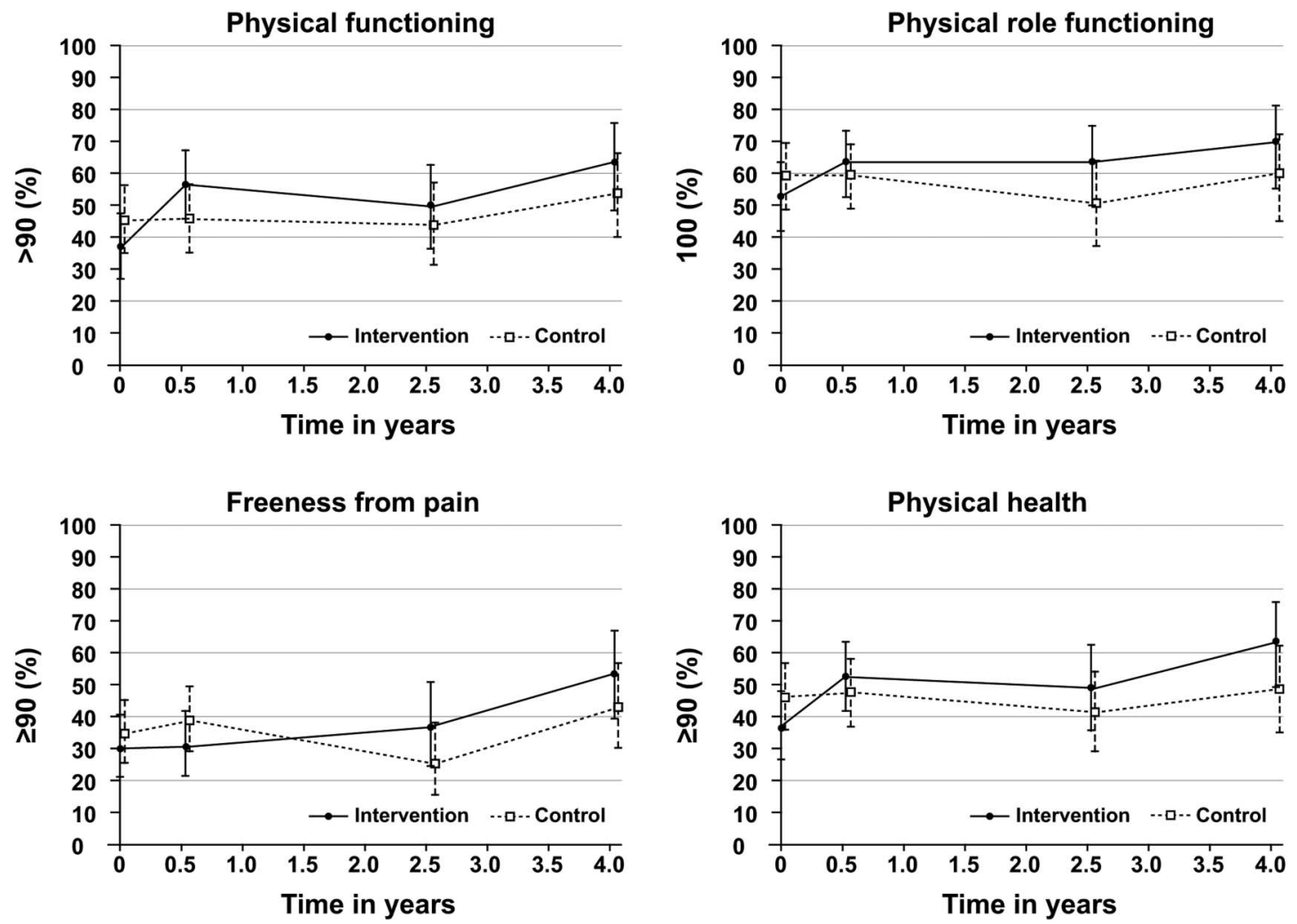

Figure 2 Proportions for the physical dimensions of quality of life (QoL) by time. Outcomes of QoL dimensions were classified into two categories according to medians. Proportions of women having higher or equal score than median are shown. Higher score defines more favourable health state.

regular smokers more often $(27.3 \%$, in contrast to $12.0 \%$ ) than the women who participated in the follow-up study.

As sensitivity analyses, we performed multilevel mixed effects logistic regression models also for women who responded to all four time points $(\mathrm{N}=75)$. When these women with non-missing responses were taken in the analyses, intervention women had significantly higher probability of improved mental health functioning (OR 1.96 ; $95 \%$ CI 1.13 to 3.40 ) as compared with control women (not shown in the figures or tables). Results from the models including only 4-year follow-up responses without 2.5 year responses were similar to the results in the current tables and figures.

\section{DISCUSSION}

The physical exercise intervention may have long-term positive effects on health-related QoL among the group of menopausal women experiencing daily symptoms of menopause. Women in the intervention group had a higher probability of improvement in physical functioning dimension of QoL from baseline to the end of 4-year follow-up. Among a subsample of women who responded to both follow-up studies, significant results between the groups were found between mental health dimensions. Overall, the results show that women in the intervention group sustained their improved QoL on both physical-health and mental-health dimensions more often than did women in the control group.

Findings from previous studies have shown that getting physical exercise is correlated with lower estimates of the perceived severity of symptoms and that exercise moderates the psychological symptoms associated with menopause. ${ }^{19^{20}}$ Our study is in line with these findings both in physical and mental dimensions. A report on an 8-year population-based follow-up study from Finland ${ }^{4}$ states that motivation to increase one's PA during menopausal transition might be an explanatory factor connected with improved QoL. According to that follow-up study, women whose PA increased or remained stable, had a higher probability of improved QoL than women whose PA decreased. ${ }^{4}$ Elavsky ${ }^{19}$ found, in a longitudinal study of middle-aged women, that PA was associated with self-worth and by this mechanism improved QoL. Furthermore, Stojanovska et al recently published a review of the role of $\mathrm{PA}$ in reducing symptoms of menopause. They considered both somatic and psychological dimensions. On the basis of their review, physical exercise has been proposed as an alternative to HRT, for improving the QoL of menopausal women.

Our study has its limitations, in the response rate $(59.7 \%)$ and the fact that women with an adverse lifestyle were more likely to be found among nonresponders. All initial participants were included in the analyses, even if they did not participate to the end of 

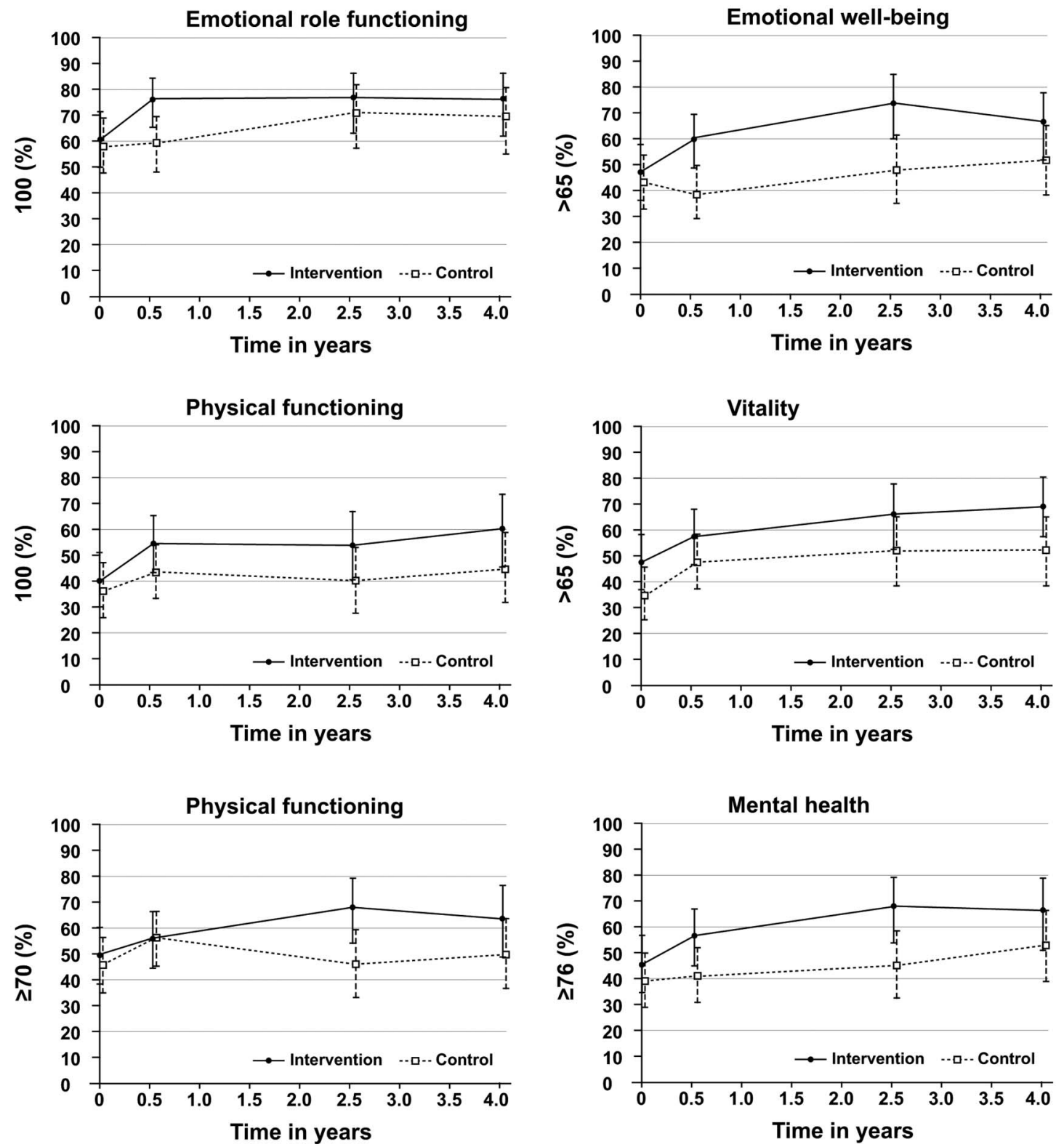

Figure 3 Proportions for mental dimensions of quality of life (QoL) by time. Outcomes of QoL dimensions were classified into two categories according to medians. Proportions of women having higher or equal score than median are shown. Higher score defines more favourable health state.

the intervention or the 2.5-year follow-up study. The results of the study showed a tendency towards increased QoL, although there were no statistically significant differences for any cores on the physical and mental dimensions of QoL between the groups. Our findings are similar to those from a large multiethnic volunteer

Table 2 Multilevel mixed effects logistic regression, ORs and 95\% Cls of physical dimensions of QoL

\begin{tabular}{lllll}
\hline & Physical functioning & Physical role functioning & Freeness from pain & Physical health \\
\hline $\mathrm{N}$ & 159 & 159 & 159 & 159 \\
Group $_{\text {baseline }}$ & $0.52(0.17$ to 1.61$)$ & $0.84(0.33$ to 2.12$)$ & $0.58(0.22$ to 1.54$)$ & $0.72(0.28$ to 1.81$)$ \\
Time & $1.03(0.10$ to 11.1$)$ & $0.93(0.75$ to 1.17$)$ & $1.07(0.85$ to 1.34$)$ & $0.97(0.77$ to 1.22$)$ \\
Groupxtime & $44.7(1.45 \text { to } 1374)^{*}$ & $1.21(0.88$ to 1.67$)$ & $1.25(0.90$ to 1.73$)$ & $1.33(0.96$ to 1.84$)$ \\
Time $^{2}$ & $0.86(0.19$ to 3.82$)$ & & & \\
Groupxtime $^{2}$ & $0.11(0.01 \text { to } 0.91)^{*}$ & & & \\
Time $^{3}$ & $1.04(0.82$ to 1.32$)$ & & & \\
Groupxtime $^{3}$ & $1.41(1.00 \text { to } 1.99)^{*}$ & & & \\
${ }^{*}$ p $<0.05$. & & &
\end{tabular}




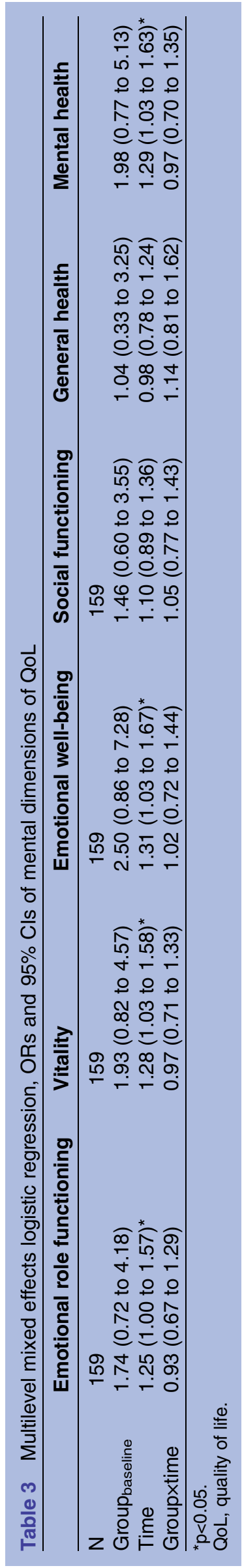

cohort of postmenopausal women, in which selfreported PA was, for the most part, stable over 8 years of follow-up. There was approximately 0.3 metabolic equivalent (MET) of actual growth in recreational PA per year $\times 8$ years $=2.4$ MET $\mathrm{h} /$ week, which represented 30 min of brisk walking in this case. ${ }^{21}$

Loss-to-follow-up analysis showed differences between participants and those lost to follow-up. Non-responding women differed from responding women in their weight, age and smoking status. Respondents were lighter, older and were less often regular smokers than non-responding women. These differences might have had an effect on the findings in the follow-up study. If all of the original participants had been studied, the differences between the groups might have been larger. When limiting the analyses to women responding to both follow-up measurements, the results differed. Explanation for this may be due to the fact that conscientious women responding to questionnaires may have benefited even more from available support to be physically active. A follow-up study in itself can be considered an intervention, producing a non-differential support to the original groups in the RCT.

The core strengths of the study reported here are its prospective study design and repeated assessments of PA behaviour, which made it possible to examine the differences between groups in the follow-up. ${ }^{17}$ Many studies have described PA patterns through the lens of crosssectional data, while fewer studies have examined changes between several time points after an intervention. PA has been reported to decrease with age, ${ }^{22}$ but contrary findings have also been reported. Earlier, our research group published the finding ${ }^{6}$ that women in menopausal transition shifted their behaviour in the other direction. Therefore, increased PA could be explained by higher motivation for lifestyle changes during the menopausal transition. In a longitudinal study by Smith-Dijulio $e t a l^{23}$ the researchers found that a woman's sense of control, of her life and satisfaction with it, and her ability to make use of the available social support, predicted greater well-being during menopause. This is consistent with our findings, as we observed improvement in vitality, emotional well-being and mental health during the follow-up, even though the results did not reach a level of statistical significance.

Our results may be generalised to menopausal women having daily vasomotor symptoms, such as hot flushes or sleep problems, according to the inclusion criteria in the original RCT. ${ }^{6}$ Overall, our study underlines the importance of PA during menopausal transition. In addition, it supports the assumption that menopause can be seen as a window of opportunity, since it may motivate women to modify their lifestyle. Menopausal women should be encouraged to participate in regular exercise and supported in this endeavour through development of easily implemented home-based exercise programmes or incorporation of PA programmes into public-health initiatives. $^{10}$ 


\section{CONCLUSION}

Women in the intervention group showed positive longterm effects on physical and mental dimensions of QoL after 4 years. Menopause is a window of opportunity for increasing PA and thereby future QoL. This finding is important, since an increase in PA may be associated with a lower future disease burden.

Acknowledgements Biomedical laboratory scientists Ulla Hakala, Ulla Honkanen and Sirke Rasinperä; research assistant Taru Helenius; and Katriina Ojala, MSc, of the UKK Institute laboratory, performed all the measurements for the research and handled contact with the participants. Anna Shefl performed language editing.

Contributors KM and RL prepared the first version of the manuscript. JR was responsible for the statistical analyses. C-HN, ET and RR participated in drafting the manuscript and have approved the final version.

Funding Financial support for the follow-up study was received from the Juho Vainio Foundation (Finland), the Pirkanmaa Competitive Research Fund (Tampere, Finland) and the Academy of Finland.

Competing interests None declared.

Patient consent Obtained.

Ethics approval The study was granted ethics approval by the Pirkanmaa Hospital District Ethics Committee, Tampere, Finland.

Provenance and peer review Not commissioned; externally peer reviewed.

Data sharing statement There are some data from the questionnaires that are unpublished but all data concerning the measurements are published.

Open Access This is an Open Access article distributed in accordance with the Creative Commons Attribution Non Commercial (CC BY-NC 4.0) license which permits others to distribute, remix, adapt, build upon this work noncommercially, and license their derivative works on different terms, provided the original work is properly cited and the use is non-commercial. See: http:// creativecommons.org/licenses/by-nc/4.0/

\section{REFERENCES}

1. Stojanovska L, Apostolopoulos V, Polman R, et al. To exercise, or not to exercise, during menopause and beyond. Maturitas 2014;77:318-23.

2. Pucci GCMF, Rech CR, Fermino RC, et al. Association between physical activity and quality of life in adults. Rev Saude Publica 2012;46:166-79.

3. Guimaraes ACA, Baptista F. Influence of habitual physical activity on the symptoms of climacterium/menopause and the quality of life of middle-aged women. Int $J$ Women's Health 2011;3:319-28.

4. Moilanen JM, Aalto A, Raitanen J, et al. Physical activity and change in quality of life during menopause-an 8-year follow-up study. Health Qual Life Outcomes 2012;10:1-7.
5. Imayama I, Alfano CM, Kong A, et al. Dietary weight loss and exercise interventions effects on quality of life in overweight/obese postmenopausal women: a randomized controlled trial. Int J Behav Nutr Phys Act 2011;8:118.

6. Luoto R, Moilanen J, Heinonen R, et al. Effect of aerobic training on hot flushes and quality of life-a randomized controlled trial. Ann Med 2012;44:616-26.

7. Mansikkamäki K, Raitanen J, Malila N, et al. Physical activity and menopause-related quality of life-a population-based cross-sectional study. Maturitas 2015;80:69-74.

8. Anderson D, Seib C, Rasmussen L. Can physical activity prevent physical and cognitive decline in postmenopausal women? A systematic review of the literature. Maturitas 2014;79: 14-33.

9. Rutanen R, Luoto R, Raitanen J, et al. Short- and long-term effects of a physical exercise intervention on work ability and work strain in symptomatic menopausal women. Saf Health Work 2014;5: 186-90.

10. Daley A, Stokes-Lampard H, Thomas A, et al. Aerobic exercise as a treatment for vasomotor menopausal symptoms: randomised controlled trial protocol. Maturitas 2013;76:350-6.

11. Thurston RC, Hadine J. Vasomotor symptoms and menopause: findings from Study of Women's Health Across the Nation. Obstet Gynecol Clin North Am 2011;38:489-501.

12. Moilanen JM, Mikkola TS, Raitanen JA, et al. Effect of aerobic training on menopausal symptoms - a randomized controlled trial. Menopause 2012;19:691-6.

13. Asikainen TM, Miilunpalo S, Oja $\mathrm{P}$, et al. Randomised, controlled walking trials in postmenopausal women: the minimum dose to improve aerobic fitness? Br J Sports Med 2002;36:189-94.

14. Heinonen $R$, Luoto $R$, Lindfors $P$, et al. Usability and feasibility of mobile phone diaries in an experimental physical exercise study. Telemed J E Health 2012;18:115-19.

15. Aalto A-M, Aro S, Teperi J. RAND-36 as a measure of Health-Related Quality of Life. Reliability, construct validity and reference values in the Finnish general population. Helsinki: Stakes, 1999; Research Reports 101.

16. Oja P, Laukkanen R, Pasanen M, et al. A 2-km walking test for assessing the cardiorespiratory fitness of healthy adults. Int $J$ Sports Med 1991;12:356-62.

17. Rabe-Hesketh S, Skrondal A. Multilevel and longitudinal modeling using Stata. 2nd edn. College Station, TX: Stata Press, 2008.

18. Newcombe RG. Two-sided confidence intervals for the single proportion: comparison of seven methods. Stat Med 1998;17:857-72

19. Elavsky S. Physical activity, menopause and quality of life: the role of affect and self-worth across time. Menopause 2009;16:265-71.

20. McAndrew LM, Napolitano MA, Albrecht A, et al. When, why and for whom there is a relationship between physical activity and menopause symptoms. Maturitas 2009;64:119-25.

21. Nguyen $\mathrm{H}$, Herting J, Kohen R, et al. Recreational physical activity in postmenopausal women is stable over 8 years of follow-up. J Phys Act Health 2013;10:656-68.

22. Pedersen P, Kjøller M, Ekholm O, et al. Readiness to change leve of physical activity in leisure time among physically inactive Danish adults. Scand J Public Health 2009;37:785-92.

23. Smith-DiJulio K, Woods NF, Mitchell ES. Well-being during the menopausal transition and early postmenopause: a longitudina analysis. Menopause 2008;15:1095-102. 


\section{Correction}

Mansikkamäki K, Raitanen J, Nygård C-H, et al. Long-term effect of physical activity on health-related quality of life among menopausal women: a 4-year follow-up study to a randomised controlled trial. BMJ Open 2015;5:e008232. There are several errors in this manuscript and are described below.

1. On page 2, 'Statistical analysis' section the following sentence is incorrect:

The odds model was used for analysis of the association between the outcomes both on the physical dimensions (physical functioning; role functioning, physical; freedom from pain; and physical health) and on the psychological dimensions (role functioning; emotional; vitality; emotional well-being; social functioning; general health; and mental health) over time and between the intervention versus the control group.

The correct sentence is:

The odds model was used for analysis of the association between the outcomes both on the physical dimensions (physical functioning; role functioning, physical; freedom from pain; and physical health) and on the psychological dimensions (role functioning, emotional; vitality; emotional well-being; social functioning; general health; and mental health) over time and between the intervention versus the control group.

2. On page 3, the sentence 'The proportions for the physical and mental dimensions of QoL by time are shown in figures 1 and 2.' should be 'The proportions for the physical and mental dimensions of QoL by time are shown in figures 2 and 3.'

3. In figure 3, the middle left panel should be titled 'Social functioning' and the lower left panel should be titled 'General health'.

4. Reference 7 is incorrect. The corrected reference is:

Mansikkamäki K, Raitanen J, Nygård C-H, et al. Sleep quality and aerobic training among menopausal women - A randomized controlled trial. Maturitas 2012;72:339-45.

BMJ Open 2016;6:e008232corr1. doi:10.1136/bmjopen-2015-008232corr1

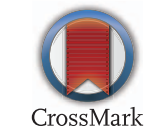

